\title{
La normativa europea procesal de contratación pública y el sistema actual de recursos contractuales
}

\author{
Santiago González-Varas Ibáñez \\ Catedrático de Derecho administrativo \\ sago_va@yahoo.esl
}

\begin{abstract}
Resumen
La jurisdicción contencioso-administrativa y el Derecho administrativo vienen configurando el sistema de control de las adjudicaciones contractuales. El nuevo Tribunal Administrativo Central de Recursos administrativos y órganos similares territoriales arraigan el Derecho administrativo en el ámbito contractual, pero pueden llegar a afectar el significado de la jurisdicción contencioso-administrativa. En todo caso, aumentan las exigencias y, en el Derecho español, esto significa que aumenta el rigor del Derecho administrativo, mientras que en otros países se oculta esta realidad en la medida de lo posible prefiriéndose enfocar la materia jurídica desde el punto de vista del Derecho de la competencia. Pese a posibles referencias en el Derecho comparado, las organizaciones del Derecho de la competencia no suponen actualmente en España crisis alguna del modelo tradicional, habiéndose llegado a la asunción de distintas parcelas o ámbitos de control. El reto en realidad es que las resoluciones que se adopten se adecuen, mejor que en el pasado, a los intereses públicos y a los de justicia de los licitadores.
\end{abstract}

Palabras clave

Jurisdicción contencioso-administrativa; control de las adjudicaciones contractuales; Tribunal Administrativo Central de Recursos administrativos; Derecho de la competencia; Derecho comparado; licitadores.

\section{European Public procurement procedural legislation and the current public procurement review system}

\begin{abstract}
The contentious-administrative jurisdiction and administrative law have been shaping the public contract awards control system. The new Central Administrative Court of Administrative Review and similar territorial bodies anchor administrative law in the public procurement sphere, but they can go as far as to affect the meaning of the contentious-administrative jurisdiction. In any case, they increase the requirements and, in Spanish law, this means increased rigour in administrative law, whilst in other countries this reality is hidden to the extent possible by preferring to approach the legal matter from the perspective of competition law. Despite possible references in comparative law, competition law organisations are not currently posing any threat to the traditional model in Spain, having assumed different domains or spheres of control. The true challenge is to ensure that the decisions adopted are more in keeping with the public interests and the justice interests of the bidders than in the past.
\end{abstract}

Key words

Contentious-administrative jurisdiction, control of public contract awards, Central Administrative Court of Administrative Review, competition law, comparative law, bidders. 
En este trabajo se aporta una explicación general de las claves del sistema de recursos que rige actualmente en España en materia de adjudicaciones contractuales, lo que lleva inevitablemente a plantear un debate jurídico comparado a la luz del Derecho europeo de contratación pública.

Comentar con cierta profundidad esta perspectiva general nos llevará a una interesante discusión entre dos posibles sistemas de control de las adjudicaciones contractuales: el judicial contencioso-administrativo o el desarrollado por órganos jurisdiccionales no incardinados en el Poder Judicial aunque con garantías de independencia.

Pero otro debate surgirá entonces cuando se descubre otra posible vía organizativa de control de las adjudicaciones, es decir, el propio Derecho de la competencia que empieza también a manifestarse a nivel comparado y en el propio Derecho español en el plano mismo organizativo del control sobre las adjudicaciones contractuales. Esto último llevará a analizar finalmente cómo en España la jurisdicción contencioso-administrativa resuelve perfectamente asuntos que podrían considerarse, incluso procesalmente, propios de tal Derecho de la competencia que cobra impulso, también en lo organizativo, con el Derecho europeo y ante ciertas tendencias jurídico comparadas que de forma relevante se han manifestado en los últimos años en Centroeuropa.

Una alusión será igualmente obligada en este contexto europeo a la jurisdicción civil en cuanto al control de las adjudicaciones contractuales al haber irrumpido aquélla también en el control de las adjudicaciones de entidades administrativas, pese a que obviamente puede afirmarse que estamos ante un control puramente accidental y no de sistema en el control de las adjudicaciones contractuales.

El debate principal, más bien, se produce entre contencioso y nuevos "tribunales" de control de adjudicaciones y, por otro lado, entre ambos y las instancias de control del Derecho de la competencia.

\section{LAS DIRECTIVAS DE RECURSOS}

Conviene hacer una referencia inicial al marco regulador general de las directivas europeas en el ámbito procesal: continúan en la actualidad vigentes tanto la directiva 89/665/CEE, del Consejo, de 21 de diciembre de 1989, para la coordinación de disposiciones legales, reglamentarias y administrativas referentes a la aplicación de los procedimientos de recurso en materia de adjudicación de los contratos públicos de suministros y de obras, que sería la directiva de recursos respecto de los sectores clásicos de contratación pública, como la directiva 92/13/CEE, del Consejo, de 25 de febrero, para la coordinación de disposiciones legales, reglamentarias y administrativas referentes a la aplicación de las normas comunitarias en los procedimientos de formaliza44 ción de contratos de la entidades que operen en los sectores del agua, de la energía, 
de los transportes y de los servicios postales que sería la directiva de recursos respecto de los sectores excluidos o especiales.

No obstante, se han reformado estas directivas de recursos, por la directiva 2007/66/CE, del Parlamento Europeo y del Consejo, de 11 de diciembre de 2007, por la que se modifican las directivas 89/665/CEE y 92/13/CEE del Consejo en lo que respecta a la mejora de la eficacia de los procedimientos de recurso en materia de adjudicación de contratos públicos.

Asimismo, téngase en cuenta la Communication intérpretative de la Comisión concernant l'application du droit communautaire des marchés publics et des concessions aux partenariats public-privé institutionalisés (PPPI) de 5 de febrero de 2008 (C(2007)6661). En esta Comunicación se pretende aclarar, ante las dudas existentes, el alcance de la aplicación de los principios fundamentales del Tratado en el ámbito de la creación de sociedades mixtas.

Por otro lado, es preciso tener en cuenta la Comunicación interpretativa de la Comisión sobre el Derecho comunitario aplicable en la adjudicación de contratos no cubiertos o sólo parcialmente cubiertos por las directivas sobre contratación pública (DOUE de 1 de agosto de 2006). En esta Comunicación se pretende aclarar, ante las dudas existentes, el alcance de la aplicación de los principios fundamentales del Tratado en aquellos ámbitos de contratación pública al que no llega la aplicación de las directivas ${ }^{1}$.

\section{CLAVES DEL NUEVO SISTEMA PROCESAL DE CONTROL DE LAS ADJUDICACIONES Y TUTELA DE LOS LICITADORES}

Una perspectiva de Derecho comparado no sitúa en mal lugar el sistema español de contratos administrativos, lo que no obsta para realizar críticas siempre que haya cuestiones mejorables.

Pero lo cierto es que en el Estado español las dos claves de la nueva regulación europea de contratación administrativa ya estaban presentes tradicionalmente, a diferencia de la mayor parte de los Estados actualmente miembros de la Unión Europea²:

1 Parece también conveniente tener en cuenta el contexto internacional donde se encuadran las directivas comunitarias, y en este sentido, cabe referirse a los acuerdos resultantes de las negociaciones multilaterales de la Ronda Uruguay 1986-1994, y en concreto al Acuerdo de contratación pública de la OMC aprobado mediante la Decisión 94/80o/CE del Consejo, de 22 de diciembre de 1994 (DO serie L 336, de 23 de diciembre de 1994, p. I), que tiene por objeto establecer un marco multilateral de derechos y obligaciones equilibrados en materia de contratos públicos con miras a realizar la liberalización y la expansión del comercio mundial. Puede asimismo citarse el Acuerdo del Espacio Económico Europeo (en vigor tras el 1 de enero de 1994), donde se prevé expresamente la apertura a la libre concurrencia de la contratación pública en los distintos países miembros (parte IV “competencia y otras normas comunes” y Anexo XVI del Acuerdo).

2 M. Bassols Coma, “Evolución sobre la legislación de contratación administrativa”, en B. Pendás García (Director), Derecho de los contratos públicos. Estudio sistemático de la Ley 13/1995, de 18 de mayo, 
Primero, la publicidad y la concurrencia y la vinculación a la mejor oferta eran reglas más que conocidas y bastante bien articuladas en la legislación tradicional de contratación administrativa, pese a que pudieran existir problemas de aplicación práctica ("problemas" éstos relativos esencialmente a ciertos abusos en cuanto a la adjudicación directa y, más recientemente, en cuanto a la personificación de entidades de Derecho privado). La esencia del sistema español de contratos administrativos se ha mantenido e incluso perfeccionado, pese a que se hayan podido introducir cambios significativos.

Segundo, el control sobre las adjudicaciones contractuales era también posible según la legislación procesal y sustantiva española en materia de control de adjudicaciones contractuales. También pudieron en este contexto manifestarse algunos problemas. En esencia el licitador que vencía en juicio podía tener dificultades a la hora de lograr una ejecución de la sentencia en sentido adecuado a su interés real. Pero resolver este problema en realidad no es fácil siquiera para las nuevas directivas europeas. Más bien es acaso el reto principal ante el que se sitúan. En todo caso, a las soluciones que dichas directivas actualmente propugnan posiblemente habría llegado la propia evolución lógica del Derecho español en materia de control de las adjudicaciones contractuales.

Es más, se dan ciertas singularidades que siguen informando de la especial evolución del Derecho español en materia contractual. Así, en nuestro país los contratos de servicios públicos se regulan como un contrato administrativo más, sin mayores excepciones o matices que los derivados de su propia naturaleza y que influyen solamente en el modo de entender la ejecución de este contrato administrativo nominado que no se separa esencialmente del régimen de adjudicación que reciben los demás contratos. En cambio, en el propio Estado francés el contrato de gestión de servicios públicos se venía tradicionalmente considerando al margen de la aplicación de las reglas de publicidad y concurrencia y vinculación a la mejor oferta. Y seguramente en este dato se encuentra la explicación de la ausencia de especial desarrollo de este contrato administrativo por parte de las directivas europeas: al seguir éstas el modelo francés resulta fácil comprender que este Derecho administrativo haya podido contagiar sus méritos y sus ausencias. En España, en cambio, reconocemos que este concreto contrato tiene algunas especificidades derivadas en el fondo de la prestación de un servicio público (que llevan a una posible mayor colaboración de la Administración en su prestación y una mayor atención por el logro de la continuidad del servicio mismo) pero sin que la posible relación intuitu personae lleve a excepcionar los principios de publicidad y concurrencia y vinculación a la mejor oferta en la fase de adjudicación.

de Contratos de las Administraciones Públicas, Barcelona 1995, pp.60 y ss.; S. González-Varas Ibáñez, Die Verwaltung in Privatrechtsform in Spanien und Deutschland, Frankfurt 2002; del mismo autor, Tratado de Derecho administrativo, Madrid 2008, Editorial Civitas, Tomo IV, Contratos; R. Gómez-Ferrer Morant (Director), Comentario a la Ley de Contratos de las Administraciones Públicas, Madrid 2004; M. Pulido Quecedo, El nuevo Tribunal Administrativo Central de recursos contractuales y la modificación de la Ley de contratos públicos y la jurisdicción contencioso-administrativa por la Ley 34/2010, de 5 de agosto, Pamplona 2010. 
En cambio, es también significativo que la gran mayoría de los Estados iberoamericanos, aunque dicen seguir el sistema contractual francés, sin embargo coinciden con las regulaciones del sistema contractual español. El contrato administrativo en la mayor parte de los Estados iberoamericanos (Argentina, Colombia, Panamá, etc.) sigue unos mismos principios que en España, con un modelo regulativo generalmente bien desarrollado en lo jurídico-administrativo. Por otro lado, los umbrales para aplicar el convenio en el sistema contractual español vienen siendo más exigentes que los de las directivas europeas para el procedimiento abierto.

El caso es que a nivel europeo se ha impuesto el contrato público. Aunque los Estados miembros puedan (por motivos históricos) no usar esta expresión, lo cierto es que, materialmente, se ha extendido esta figura jurídico-administrativa por Europa considerando que todo modelo legislativo nacional ha de seguir los tres principios que definen la esencialidad de este contrato frente al contrato civil (publicidad, concurrencia y vinculación a la mejor oferta), principios que expresan tanto una máxima concurrencial como una regla de legalidad pública.

Si el contrato administrativo y no el civil de la Administración se ha impuesto en un contexto europeo e internacional ello se debe a que el mercado interior se realiza sólo si se cumplen las reglas propias del contrato administrativo de publicidad, concurrencia y vinculación a la mejor oferta, ya que de lo contrario se contrataría en clave nacional siempre que el adjudicador así lo quisiera y no se realizaría tal mercado.

Esta puesta en valor del contrato administrativo en un contexto comparado se refuerza, además, si se considera que el dato de la paridad entre las partes (propio del contrato civil) no se ha manifestado como se piensa habitualmente en tales modelos de contrato civil de la Administración, al ser constantes e inevitables las prerrogativas de la Administración y así lo atestigua un conocimiento de la realidad contractual de Derechos como el británico o el alemán (me remito a mi Tratado de Derecho administrativo, tomo IV, contratos, Edit. Civitas, Madrid, junio 2012, 2. edición).

En lo procesal, el modelo español consiste tradicionalmente en un control de la jurisdicción contencioso-administrativa. De este modo, se consigue en principio el mejor de los posibles modelos de control de las adjudicaciones contractuales, ya que el modelo judicial es el que mayores garantías otorga tanto por su imparcialidad como por su neutralidad y calidad del control. Además se desarrolla dicho control por una jurisdicción adecuada a los intereses llamados a enjuiciar en los procesos en cuestión. Históricamente este modelo significa precisamente la superación de posibles sistemas anteriores de control de jurisdicciones especiales sin las garantías propias de un órgano judicial, que acaban de exponerse. Es claro que en la mayor parte de los Estados europeos no se contaba con un sistema tan avanzado de garantías al menos en los años en que estuvo vigente la Ley de jurisdicción de 1956. 
Este modelo judicial está previsto desde el origen de la regulación procesal de las directivas europeas de recursos aunque, ante la realidad existente en la mayor parte de los Estados, dichas directivas de recursos abrieron la posibilidad de instaurar un modelo alternativo de control regido por autoridades administrativas siempre que reunieran las garantías de independencia que constaban en el articulado de las propias directivas y en la jurisprudencia del Tribunal de Justicia de Luxemburgo.

En definitiva, en Europa el seguimiento de un régimen jurídico materialmente público basado en las reglas de publicidad, concurrencia y vinculación a la mejor oferta en la fase de adjudicación ha venido acompañado de un régimen también materialmente público de control sobre las adjudicaciones contractuales. El hecho de controlar una adjudicación manifiesta por si mismo una ratio de Derecho público. En un contrato civil no se controlan necesariamente las adjudicaciones. La iuspublificación se produce por tanto en lo material como en lo procesal aunque buena parte de los Estados europeos hayan intentado obviar la significación pública de este componente inherente a las características de la nueva regulación europea.

Por contrapartida, ocurre que en aquellos Estados que han tenido que instaurar prácticamente ex novo el sistema procesal (y donde en verdad se ha sufrido una revolución jurídica en el ámbito contractual de la Administración y sus entidades dependientes: Alemania, Austria, etc.) se ha tenido la oportunidad de instaurar un nuevo modelo sin el lastre de condicionantes históricos. Y seguramente por ello actualmente han conseguido instaurar un modelo jurisdiccional que puede ser incluso referencia obligada actualmente en un contexto jurídico europeo para Estados como el español donde la tradición era más acorde con las propias directivas, lo cual no deja de ser una paradoja.

El debate de interés actualmente a nivel europeo es el de la elección por el sistema judicial de control de las adjudicaciones, o por el sistema de jurisdicción administrativa no judicial; o por un sistema mixto o intermedio donde conviven ambos pero otorgando más peso y garantías al control por órganos puramente adminsitrativos.

Es claro que lo ideal y más perfecto es en principio el control judicial donde el grueso de la supervisión de las adjudicaciones recae en jueces. La calidad del control aumenta si además tales jueces pertenecen al orden contencioso-administrativo, al ser éste adecuado al carácter o naturaleza de los asuntos que tienen que ser resueltos.

Pero con el devenir de los tiempos se ha manifestado un problema de operatividad de la jurisdicción contencioso-administrativa que no consigue resolver lo prioritario o más elemental en esta materia, es decir, la adecuación entre el fallo y el interés real del sujeto. En definitiva, todos sabemos que la jurisdicción contencioso-administrativa, pese a gozar en principio de las mayores garantías, es decir, las inherentes a su carácter judicial y adecuación a la naturaleza de los asuntos enjuiciados, sin embargo no siempre consigue satisfacer el interés real del recurrente cuando vence en jui48 cio (la obra estará terminada, el suministro ejecutado, etc.). Y se convierte en "regla 
general" la posible conversión de la justicia primaria en secundaria, mediante el otorgamiento de indemnizaciones compensatorias tras la anulación de la adjudicación (es decir, un porcentaje legalmente establecido por beneficio industrial o lucro cesante), con la desventaja asimismo del sobrecoste para el erario público. Tampoco las medidas cautelares son una solución plenamente satisfactoria para resolver este problema, pues además de que pueden perjudicar el interés público, su concesión puede ser excepcional y además implican muchas veces problemas de fianzas y contracautelas de notoria complejidad en la práctica para el recurrente.

En este contexto se entiende que finalmente, a modo de una rendición de principios, pero con sentido práctico, se introduzca finalmente en España el Tribunal Administrativo Central de Recursos contractuales (art. 311 de la Ley 34/2010, de 5 de agosto) y tribunales similares a nivel regional.

Este nuevo sistema refuerza la vía administrativa que, tradicionalmente, venía siendo, en términos prácticos, un pasatiempo en el sistema de control de las adjudicaciones, ya que resolvía el mismo órgano que dictaba el acto. En definitiva, un modelo bien conocido por todos, por sus insuficiencias, y cuyo sentido no era otro que el de abrir paso a la vía judicial, sobre la que recaía, con sus grandezas y limitaciones, el peso del control jurídico de la adjudicación y la tutela de los intereses legítimos de los licitadores.

Ahora, en cambio, de lo que se trata es de reforzar el control en vía administrativa, continuando el paso inicial que dio en esta dirección el artículo 37 de la versión anterior (a la reforma de la Ley 34/2010) de la Ley de contratos del Sector Público 30/2007, que, ya por entonces, dejaba apreciar esta posibilidad de profundizar en este tipo de soluciones hasta llegar a un "Tribunal" Administrativo Central de Recursos contractuales u órgano administrativo independiente sobre el cual hacer gravitar el control de las adjudicaciones contractuales.

Las referencias o conexiones del actual "Tribunal" son, pues, claras. Primeramente, las propias directivas de recursos: desde su primera versión han contemplado esta alternativa. Las cada vez mayores exigencias que en lo procesal impone el Derecho europeo (vid. la nueva directiva 2007/66/CE de 11 de diciembre de 2007) terminan provocando la creación de un órgano más adecuado, en su funcionamiento, a las exigencias de la justicia administrativa de los licitadores y del interés público, con plazos más adecuados, cortos y matizados y con un régimen de suspensión cautelar general e incluso con la previsión de medidas preventivas, que se imponen desde Europa.

En segundo lugar, otro punto de referencia puede ser el de las instancias administrativas de control del Derecho de la competencia o de mercados o servicios de interés general, dentro pues del propio Derecho español. El Tribunal de Recursos contractuales puede llegar a tener un desarrollo similar en materia de control de las adjudicaciones, tendencia que es irremediable, a no ser que el arraigo histórico de lo 
contencioso-administrativo en la materia contractual pueda terminar pesando, manteniéndose en lo contractual un mayor protagonismo del contencioso que en aqueIlas otras áreas. Observemos qué ocurre con el Derecho de la competencia, donde el peso del control recae en la CNC, teniendo las sentencias de la jurisdicción contencioso-administrativa (a través de la Audiencia nacional o del Tribunal Supremo), un valor a veces puramente testimonial o reiterativo de lo resuelto por aquella otra instancia de control. Según esto, el contencioso-administrativo tendría un papel más reducido, y puramente jurídico, centrándose en la depuración de posibles vicios de entidad puramente jurídica. En cambio, todavía actualmente, conforme al modelo tradicional de las Leyes jurisdiccionales de 1956 y 1998, en sede contenciosa se enjuician todos los elementos de juicio, incluidos los aspectos técnicos, con la ayuda de pruebas periciales que, como es notorio, a veces pueden protagonizar el escenario de la justicia, optando muchas veces el juzgador (en especial cuando existe pericial judicial) por una remisión a tal informe.

En todos estos casos en que se descarga el peso del control hacia la vía administrativa o hacia un órgano no judicial, no podemos pretender (por pura lógica) una duplicidad de controles, es decir, un control judicial con igual intensidad que el llevado a cabo por la instancia administrativa especializada en la materia contractual. El papel del órgano jurisdiccional vendría así a reducirse a una función de comprobación puramente jurídica, de forma similar a como ocurre cuando se impugna un laudo arbitral, limitándose el órgano judicial a la posible observancia de vicios jurídicos graves o de nulidad.

En tercer lugar, otra referencia es, a nivel jurídico comparado, la que aportan los Estados de Centroeuropa, donde llevan ya años aplicando una regulación de características muy próximas a la que se acaba de introducir en España por la reforma de la Ley 30/2010 en cuanto al régimen de plazos de recursos y de medidas cautelares. Como antes advertíamos en tales Estados la ausencia de tradición histórica ha podido favorecer la pronta instauración de este tipo de modelos (de control no judicial de las adjudicaciones contractuales) que pretenden lograr una mayor adecuación con el interés real del sujeto y con ello una justicia primaria y no secundaria.

Otra solución distinta a la articulada por la Ley 30/2010 habría sido la de instaurar un "proceso especial" dentro de los procesos especiales de la jurisdicción contencioso-administrativa, en este ámbito del control de la adjudicaciones contractuales; pero es discutible, como ya hemos comentado, que la jurisdicción contencioso-administrativa pueda cumplir por entero las distintas exigencias que imponen las directivas europeas, en especial de la directiva $2007 / 66$.

Esta tendencia de instaurar un Tribunal español Administrativo Central de Recursos contractuales tras la Ley 30/2010 se advierte en distintos Estados y no sólo europeos, como ilustran perfectamente los casos de Panamá y de Perú, donde ha decaído el peso del control judicial y se ha trasladado en gran medida a instancias de control 50 próximas al actual Tribunal español Administrativo Central de Recursos contractuales. 
En Alemania esta instancia administrativa de control de las adjudicaciones se ha incardinado dentro del Tribunal de Defensa de la Competencia. Después de amplio debate y de ciertos cambios organizativos se ha consolidado este sistema. Por encima se prevé un control de la jurisdicción civil, pero este dato no puede llevar a equívocos. El control de las adjudicaciones contractuales se viene realizando desde el Kartellamt. El control civil tiene y siempre tuvo un carácter simbólico en este ámbito. Y cuando se desarrolló históricamente corroboró la imposibilidad de un control de justicia primaria o anulatoria adaptada al interés del sujeto, porque abiertamente en sede jurisdiccional civil se convierten las pretensiones de tal carácter en pretensiones indemnizatorias: mediante un característico juicio prejudicial de la materia administrativa se verifica por el órgano judicial civil la improcedencia de la adjudicación, a efectos entonces de otorgar justicia al modo civil, ya que evidentemente tal jurisdicción no puede dedicarse a anular actos de adjudicaciones ni puede pretenderlo. Las insuficiencias son notorias, como claramente puede apreciarse. Pero el caso es que ni siquiera históricamente podemos decir que en Alemania este tipo de control consiguiera erigirse en un posible modelo. Más bien, incluso de esta forma, este control civil fue principalmente inoperante. No obstante, es interesante descubrir cómo funciona un control genuinamente civil en materia administrativa en aquellos ámbitos en los que no exista una jurisdicción administrativa llamada a ejercer con garantías su jurisdicción. En general, en tales casos la jurisdicción civil ejerce una función de garante del sistema judicial, declarando abierta su jurisdicción por el hecho de que no se prevé un contencioso-administrativo que tutele los derechos de los particulares, desarrollando entonces aquella un control prejudicial sobre las materias administrativas de necesario conocimiento (para que el justiciable pudiera tener una cierta tutela judicial) a fin de concluir con pronunciamientos resarcitorios e indemnizatorios. El contencioso-administrativo en Alemania (donde el Derecho civil de la Administración tuvo un mayor alcance que en España) se reservó históricamente a las relaciones jurídicas marcadas por una idea de subordinación entre Administración y administrado. La materia contractual, en cambio, quedó afectada por este sistema civilista en ámbito contractual “administrativo". El influjo de la doctrina de O. Mayer es más que notorio.

Actualmente en Alemania el control se desarrolla por instancias que se incardinan dentro de los órganos administrativos de control del Derecho de la competencia. En todo caso, en Alemania, cuando se reforma el control de las adjudicaciones a raíz de un decisivo contencioso en el que resulta vencedor la Comisión Europea frente al Estado alemán en el año 1995 (seguido de otros en los años inmediatamente posteriores), se descartó la vía del contencioso-administrativo. Como no pudo mantenerse la esencialidad civil, finalmente se desarrolló un sistema puramente administrativo de control de las adjudicaciones contractuales basado en un control realizado por instancias de tal carácter ministerial, acorde por lo demás a la naturaleza administrativa de este tipo de actos de adjudicación contractual. Quizás no se reconozca abiertamente este hecho de la iuspublificación, en los manuales al uso (que empiezan sólo desde hace pocos años a proliferar en Alemania) sobre la contratación administrativa (evitándose por cierto esta terminología, ya que el "Verwaltungsvertrag" en el Derecho alemán no tiene nada que ver con nuestro contrato administrativo, al cual desig- 
nan con diversos nombres, siendo el más común el de "encargos públicos" öffentliche Aufträge, o Beschaffungswesen o Vergaberecht), pero la realidad es que, se quiera o no, se ha consagrado un sistema "administrativo" de control (el Vergabekammer en el nivel regional y en el Budeskartellamt a nivel estatal, arts. 102 y ss. y 97 y ss. respectivamente de la Ley contra las limitaciones a la competencia).

Más que profundizar en la relación del contrato administrativo con el contrato civil (tema éste que actualmente carece de interés en España), puede profundizarse (por su mayor interés) en la relación del contrato administrativo y su sistema de control de adjudicaciones con el Derecho de la competencia. De forma significativa, en el Derecho alemán, ante el fracaso que tuvo la "tesis civilista" ante el Tribunal de Justicia de la Unión Europea, se opta por profundizar en el Derecho de la competencia para regular las claves del modelo organizativo de recursos y el control sobre las adjudicaciones. Es claro que el Derecho europeo lleva a marginar la relevancia de los aspectos privados pero también lo es que no provoca por ello la necesaria afirmación de un modelo formal de Derecho administrativo (formalmente, en realidad, la cuestión le es indiferente al Derecho europeo). Pero materialmente sí afirma el Derecho europeo principios de legalidad pública, como ya nos consta, para configurar los contratos de la Administración.

\section{LA RATIO DE LA COMPETENCIA EFECTIVA}

En todo caso, esta consideración del contrato administrativo bajo la lógica del Derecho de la competencia no deja de tener en cambio interés para nosotros.

Es claro que en España, al igual que en el resto de Europa, siempre ha estado presente que el Derecho europeo es ante todo un Derecho de la competencia. Pero no hemos llegado a reflexionar sobre la posibilidad de ordenar los contratos administrativos (y menos su sistema de control) bajo esta ratio. Desde luego, Europa no obliga a esta consideración de los contratos bajo el Derecho de la competencia, si bien, como es sabido, sí obliga a respetar principios que materialmente hablando son también propios del Derecho de la competencia: es decir, las directivas pretenden tanto la concurrencia efectiva entre licitadores como indirectamente la legalidad de la adjudicación contractual. El caso es que lo primero (la concurrencia), en Derechos como el español, queda a cubierto incidiendo en lo segundo (la legalidad).

En el caso del Derecho español podemos reconocer "interferencias" del Derecho de la competencia en un ámbito jurídico-administrativo dominado por la ratio de la legalidad pública. Sin embargo, también cabría ordenar los contratos (su fase esencial de adjudicación) desde la ratio de la competencia para llegar a un mismo resultado. No deja de ser singular esta posible impronta reguladora -del sistema contractualpor parte del Derecho de la competencia. Para nosotros es innecesario este enfoque porque el desarrollo del Derecho administrativo cubre perfectamente los mismos in-

52 tereses que cubre el Derecho de la competencia allí donde no había tradición jurídico- 
administrativa en el ámbito de los contratos de la Administración. Es decir que de este modo se consigue evitar reconocer abiertamente algo que es irremediable, es decir, la iuspublicación de los contratos. El tema es propio de la competencia.

Todo esto no impide para que en el Derecho español el Tribunal de Defensa de la Competencia -TDC-, primeramente, y la Comisión de Defensa de la Competencia -CNC-, con posterioridad ${ }^{3}$, hayan realizado incursiones en la materia jurídico-administrativa contractual, afectando a la propia fase de adjudicación.

Pensamos que puede tener interés profundizar seguidamente en este aspecto, con algunos ejemplos de resoluciones de tales entidades administrativas (TDC y CNC) refrendadas por los órganos jurisdiccionales del orden contencioso-administrativo. Pero, en todo caso, nos parece claro que, pese a la posible vis expansiva del Derecho de la competencia, el sistema de la contratación administrativa no precisa ordenación alguna bajo esta lógica, sino corrección, eso sí, de algunos posibles extremos en que pueda incidir tal Derecho para mejorar aspectos de las adjudicaciones. En todo caso, la ratio es la legalidad administrativa y su aplicación consigue la realización misma de la regla de la concurrencia. Se controla la adjudicación como acto administrativo que es, simplemente. $Y$ los tres principios que diferencian esencialmente el contrato administrativo del civil (publicidad, la propia concurrencia y la vinculación a la mejor oferta) son reglas de legalidad administrativa aunque puedan tener un sentido concurrencial.

Hechas estas precisiones podemos ejemplificar, bajo las apreciaciones anteriores, estas afirmaciones que acaban de hacerse. No es infrecuente que la CNC tenga que entrar a determinar si en el marco de la contratación administrativa los licitadores incurren en prácticas colusorias vulneradoras del artículo 1 de la LDC, artículo que prohíbe todo acuerdo que tenga por objeto, produzca o pueda producir el efecto de impedir, restringir o falsear la competencia en todo o parte del mercado nacional y, en particular, los que consistan, entre otros, en la fijación, de forma directa o indirecta, de precios o de otras condiciones comerciales o de servicio.

La concertación horizontal de precios constituye una de las infracciones más graves de la Ley de Defensa de la Competencia, pero, según la propia CNC "la gravedad es considerablemente mayor en el supuesto de concertación para ofertar los mismos precios en un concurso (bidrigging), ya que en este supuesto la sustitución de la competencia se realiza en un terreno en el que la afectación del interés público resulta especialmente relevante. Si una Administración pública convoca un concurso para obtener precios más bajos en los suministros, y esa finalidad es vetada por el

3 La Ley de Defensa de la competencia (LDC) de 3 de julio de 2007, que entró en vigor el 1 de septiembre de 2007, sustituye o deroga la precedente de 17 de julio de 1989, reformada sensiblemente por la Ley 52/1999, de 28 de diciembre. La Comisión Nacional de la Competencia presenta una estructura piramidal centrada en la existencia de dos órganos separados, la Dirección de Investigación y el Consejo, que realizan con independencia sus respectivas funciones de instrucción y resolución bajo la supervisión y coordinación del Presidente, apoyado en un conjunto de servicios comunes. 
acuerdo entre los concursantes, el interés público resulta dañado doblemente ya que, por un lado, se distorsiona el funcionamiento del mercado, al igual que en cualquier otra conducta colusoria y, por otro, se evita el ahorro público perseguido por la convocatoria del concurso, al impedir ofertas más bajas de las convenidas".

Para probar los acuerdos colusorios y anticompetitivos es prácticamente imposible contar con medios de prueba como documentos, testigos y, menos aún, con la confesión de los acusados, pues difícilmente los autores de actos colusorios dejarán huella documental de su conducta restrictiva o prohibida, la cual únicamente podrá extraerse de indicios o presunciones. Por este motivo en el caso de los acuerdos o prácticas colusorias ha de recurrirse casi siempre a la prueba de presunciones.

Negar validez a estas pruebas indirectas conduciría casi a la absoluta impunidad de actos derivados de acuerdos o conciertos para restringir el libre funcionamiento de la oferta y la demanda. De hecho, la utilización de la prueba de indicios o presunciones ha sido confirmada y reconocida por una muy consolidada jurisprudencia nacional y comunitaria.

Así, por ejemplo, en nuestro país en la Resolución del TDC de 4 de julio de 1988 (Prensa dominical), confirmada por Sentencias del Tribunal Supremo de 6 de octubre y 5 de noviembre de 1997; en la Resolución de 2 de noviembre de 1988 (Prensa del corazón) que ha sido confirmada por las Sentencias de la Audiencia Nacional de 10, 22 y 30 de marzo de 1993 y del Tribunal Supremo de 15 de septiembre de 1997; en la Resolución de 15 de septiembre de 1988 (Vacunas antigripales) que, recurrida ante la Audiencia Nacional, fue confirmada por Sentencia de 6 de mayo de 2002; en la Resolución de 8 de julio de 1992 (Expte. 294/91, subastas de aceite de oliva); en la Resolución de 30 de septiembre de 1998 (Expte. 395/97, Vacunas Antigripales), confirmada por la sentencia de la Audiencia Nacional de 18 de febrero de 2003 y por la Sentencia del TS de cinco de abril de 2006 RJ 2006|1946; en la Resolución (Expte. 476/99, Agencias de Viaje) de 25 de octubre del año 2000; en la Resolución de 22 de julio de 2004 (Expte. 565/03, materiales radiactivos), confirmada por la Sentencia de la Audiencia Nacional de 17 de abril de 2007 recurso $n^{\circ} 468$ /2004; etc.

A esta práctica también ha recurrido repetidamente el Tribunal de las Comunidades Europeas, entre otras, en las Sentencias de 16 de diciembre de 1.975 en el asunto Suikier, de 14 de julio de 1.977 en el asunto Materia Colorantes, de 14 de julio de 1.981 en el asunto A.G. Zuechner contra Bayerische Vereinsbank AG., de 7 de junio de 1.983 en el caso Hi-Fi Pioneer, 21 de febrero de 1.984 en el asunto Hasselblad, etc.

Según tal jurisprudencia, aunque es una prueba que debe utilizarse con extrema precaución, la doctrina del Tribunal Constitucional y del Tribunal Supremo considera que el derecho a la presunción de inocencia no se opone a que la convicción judicial en un proceso pueda formarse sobre bases indiciarias: "Lo que es preciso para usar esta prueba, como ha dicho la jurisprudencia constitucional, es que se parta de hechos bá-

54 sicos objetivamente acreditados y que la inferencia lógica que parte de esos hechos no 
sea irrazonable ni irrazonada. Exigencias similares a las del Código Civil (artículo 1.249 y 1.253) de que sólo se admitan cuando el hecho de que han de deducirse esté completamente acreditado y que entre éste y el que se trata de deducir haya un enlace preciso y directo según las reglas del criterio humano". Según la doctrina del Tribunal Constitucional la aceptación de la prueba de presunciones en derecho punitivo o sancionador exige el cumplimiento de tres requisitos: en primer lugar, que los hechos base, es decir los indicios, estén plenamente demostrados, que la relación causal entre los hechos y los indicios esté suficientemente razonada y, finalmente, que si existen otras razones para explicar los indicios, deben ser analizadas y explicarse la causa de su rechazo (Sentencias del Tribunal Constitucional 174/85 y 175/85, ambas de 17 de diciembre, la 169/1986, de 22 de diciembre y la 150/1987, de 1 de octubre).

Por ello, la actual CNC ha establecido en diversas Resoluciones que las pruebas indiciarias sólo pueden servir de base de imputación si no hay otra explicación lógica alternativa de los hechos. Si ésta existe, debe prevalecer y llevar a la conclusión de que no se ha producido infracción.

Cabe igualmente destacar que "la infracción consiste en la concertación para presentarse al concurso, siendo indiferente a los efectos de constatar la vulneración del artículo 1.1.a) LDC que se haya producido o no la adjudicación, pues la infracción consiste en la adopción de un acuerdo que tiene como objeto la limitación de la competencia en precios, con independencia de cuál haya sido su resultado. Son, en consecuencia, autores de las respectivas infracciones quienes se presentaron ofertando precios concertados a cada uno de los concursos".

Así pues, el Derecho de la competencia, y sus instancias nacionales (o, por cierto, también regionales -en auge-) de control "interfieren" en el plano procesal o de control de las adjudicaciones, como lo ejemplifica este supuesto, o alguno más que en la práctica se manifiesta. Es decir, una determinada parcela ha conseguido el Derecho de la competencia en el Derecho español. Pero es claro que los temas de concurrencia efectiva, en nuestro ordenamiento, se resuelven por el Derecho administrativo desde el punto de vista de un enjuiciamiento de legalidad administrativa de tales adjudicaciones, pese a que pudiera considerarse que existen componentes claros de posible enfoque a través de aquellas otras instancias de control. En este sentido, el especial desarrollo en el Derecho administrativo, de los principios generales del Derecho ${ }^{4}$, propicia que por esta vía jurisdiccional administrativa (o, en su apoyo, los nuevos Tribunales de control de adjudicaciones contractuales) se solucionen todos los problemas jurídicos fundamentales en el plano de las adjudicaciones, e incluso en el plano de la ejecución del contrato. En definitiva se enjuician asuntos materialmente iguales, pero desde distintos puntos de vista: en el control de la jurisdicción contencioso-administrativa pueden ser claves los principios generales del derecho administrativo (interdicción de la arbitrariedad, motivación

4 E. García de Enterría / T.R. Fernández Rodríguez, Curso de Derecho administrativo, 12 edición Madrid 2004 p. 87. 
suficiente, etc.) mientras que en el control de las instancias de la competencia puede ser clave el abuso de posición dominante, bajo un mismo fondo que es la tutela efectiva y la igualdad de los licitadores.

En todo caso, como hemos podido comprobar, el histórico debate entre el posible modelo público o privado de control (jurisdicción administrativa o jurisdicción civil) ha cedido paso a este otro debate de interés entre jueces administrativos u órganos administrativos independientes, destacando dentro de estos últimos la opción de una mayor atribución competencial a favor de la Comisión Nacional de la Competencia y órganos equivalentes autonómicos.

El propio TDC (actualmente, Comisión Nacional de la Competencia) ha reconocido, como es lógico, que las posibles impugnaciones en materia de contratación administrativa han de realizarse ante la jurisdicción contencioso-administrativa (pueden verse las resoluciones del TDC de 2 de marzo de 1998, expediente R 275/97; de 12 de junio de 1998, $A A$ 48, diciembre 1998-enero 1999 § 937, pp.3627 y ss.; y de 23 de junio de 1998, $A A 21999$ § 36 p.116; resolución del TDC de 22 de octubre de 1998, expediente $\mathrm{R}$ 298/98).

Sin embargo, son destacables las incursiones del TDC (hoy CNC) que hemos comentado anteriormente junto a otras posibles (resolución de 23 de junio de 1998, $A A$ $21999 \S 36$ p.116, etc.).

Otro de los pilares de la LDC lo constituyen los falseamientos de la libre competencia por actos desleales, que puede tener incidencia en las adjudicaciones contractuales. La nueva regulación se contiene en el artículo 3 de la LDC de 2007 ("Falseamiento de la libre competencia por actos desleales): "La Comisión Nacional de la Competencia o los órganos competentes de las Comunidades Autónomas conocerán en los términos que la presente Ley establece para las conductas prohibidas, de los actos de competencia desleal que por falsear la libre competencia afecten al interés público".

La jurisprudencia ha venido exigiendo la necesidad de que no se realicen prácticas desleales que pueden ser de muy diverso tipo, tales como declaraciones que consigan injustificadamente apoyar o desprestigiar a los competidores, según se afirma por ejemplo en la sentencia de la Audiencia Nacional (Sala de lo Contencioso-Administrativo) de 28 enero 2005, JUR 2005/2090185.

5 Esta sentencia, confirmando la doctrina del TDC, considera un acto de competencia desleal que falsea de manera sensible la libre competencia afectando al interés público, una campaña de desprestigio contra competidores mediante la publicación de anuncio en prensa, porque es un acto susceptible de distorsionar gravemente la competencia, considerando entonces la infracción como existente, "perturbando gravemente la estructura del mercado y afectando al interés público al obstaculizar la existencia de una competencia suficiente en el mismo".

Asimismo, el TDC, en su resolución de 26 febrero 2004 (AC 2004l328) declara contraria al Derecho de la competencia una "ventaja competitiva adquirida por el infractor". El mismo TDC, en su resolución de 1 abril 2004 (AC 2004|811) estima que son desleales las "campañas de publicidad que producen confusión en el usuario" “y denigran a los competidores". También se ha considerado desleal la "difusión que presenta 
Se produce una contravención de la competencia, por desleal, cuando se vulneran las reglas de la buena fe y se pone en perjuicio a una determinada competidora en el mercado, así por ejemplo cuando se producen manifestaciones dirigidas a menoscabar la reputación de un tercero con finalidad concurrencial, (sentencia del Tribunal Supremo de 11 de julio de 2006 JUR 2006/4977).

La falta de imparcialidad de alguna autoridad que pueda influir en la adjudicación podría censurarse por esta vía o por el cauce ordinario contencioso-administrativo (STSJ de 6 de junio de 2003 de la Comunidad Valenciana; STS de 27 de marzo de 2007 RJ 2007/3149).

En el marco de la competencia desleal a la luz de las resoluciones del TDC (hoy Comisión Nacional de la Competencia) el Derecho de la competencia intervendría contra los comportamientos denunciados si concurren las siguientes circunstancias: a) Que sean constitutivos de competencia desleal. b) Que puedan producir un falseamiento sensible de la libre competencia en todo o en parte del mercado nacional. c) Que por su dimensión o intensidad provoquen una afectación del interés público. La declaración de desleal ha venido declarándose directamente por el TDC, cuando entre dentro de su ámbito de competencia, sin necesidad de una previa declaración como desleal por parte de la jurisdicción civil.

Como decimos, este control del Derecho de la competencia se relaciona bien con la propia lógica procesal existente en el Derecho europeo desde su origen, considerando la similitud de este control y el que desarrolla en Europa el TJUE. Pero la conclusión es clara en el sentido de que la jurisdicción contencioso-administrativa, o el nuevo sistema de tribunales de control de las adjudicaciones contractuales es, al menos actualmente, más adecuado y completo porque permite resolver los mismos intereses que aquellos que plantea el Derecho de la competencia al tiempo que considera los específicamente administrativos. El debate de futuro está abierto pero la tradición pesa en todo este ámbito procesal.

\section{EL VALOR EN ESPAÑA DEL DERECHO DE LA COMPETENCIA EN MATERIA DE CONTROL DE ADJUDICACIONES CONTRACTUALES}

El valor principal que aporta el control del Derecho de la competencia está en la contratación de entidades dependientes de la Administración que no desarrollen funciones de satisfacción de interés general, es decir, que tengan por tanto carácter industrial y mercantil.

como cierta, no siéndolo, la exclusividad o reserva de funciones de intermediación inmobiliaria para quienes tengan el título API, ya que menoscaba la credibilidad de los demás profesionales que legítimamente intermedian en el mercado inmobiliario, por ser un acto de engaño y denigración" (TDC, resolución de 4 julio 2003. AC 2003|1108). 
Es sabido que tras las directivas comunitarias, junto al Estado y los entes públicos territoriales, han de considerarse también poder adjudicador los "organismos públicos". El quid es el nuevo criterio funcional que sirve para definir el organismo de Derecho público. Se sigue, en efecto, una "definición funcional del organismo de Derecho público como poder adjudicador": las directivas comunitarias se aplicarán si dicho organismo ha sido "creado para satisfacer una necesidad de interés general que no tengan carácter industrial y mercantil”. Lo decisivo es el tipo de función de la entidad: si es puramente mercantil el sujeto quedará fuera del ámbito de aplicación de la norma. Si se corresponde con un "interés general” aquél deberá cumplir las directivas. Pero, obviamente, no todo tipo de organismo que cumpla esta función queda sujeto al régimen comunitario de contratación pública. Es precisa una previa adscripción o vinculación del organismo a un poder público (Estado, ente territorial u otro organismo de Derecho público). De ahí que, junto al requisito obligado de estar dotado de personalidad jurídica, las directivas insistan asimismo en dicha vinculación a un sujeto público. Concretamente ha de presentarse una de las tres circunstancias siguientes:

- Que el organismo tenga una actividad mayoritariamente financiada por el Estado, los entes públicos territoriales y otros organismos de Derecho público.

- Que su gestión se halle sometida a un control por parte de estos últimos.

- Que su órgano de administración, de dirección o de vigilancia esté compuesto por miembros de los cuales más de la mitad sean nombrados por el Estado, los entes públicos territoriales u otros organismos de Derecho público ${ }^{6}$.

Este planteamiento no sólo se corrobora desde el punto de vista de la legislación adminsitrativa contractual o europea sino también desde el punto de vista de la legislación de Defensa de la competencia?.

6 Artículo 1.9 de la directiva 2004/18.

7 La identificación de una actividad con repercusión en lo económico, y con ello de la condición de empresario, conduce al sometimiento de quien la realiza al control del Tribunal de Defensa de la Competencia (resolución de 27 de julio de 1993, expediente A 59/93). Puede citarse también la resolución de 20 de marzo de 1998 ( $A A 371998$ § 723):"En Derecho comunitario de la competencia el concepto de empresa comprende cualquier entidad que ejerza una actividad económica con independencia del estatuto jurídico y de la forma de financiación de dicha entidad. No existen razones para que la interpretación a la que haya de llegar el Derecho español difiera de la solución dada en Derecho comunitario" (...). Se aplica el Derecho comunitario de la competencia cuando "las Administraciones públicas, cualquiera que sea la forma que adopten, actúen como operadores económicos cuya conducta incida en la estructura y el funcionamiento del mercado".

Puede también consultarse la resolución de 25 de octubre de 2000 (expediente R 393/99, con el antecedente de la resolución de 27 de enero de 1999, expediente r336/98). La función de la Comisión Nacional de la Competencia (anteriormente Tribunal de Defensa de la Competencia) no es sino la de velar por el respeto de las reglas de la competencia (tal como sienta la resolución de 18 de octubre de 1993 del TDC, expediente A. 58/93, Sabadell y de 25 de julio de 1990, expediente 268/90 y 551789). 
Pues bien, cuando la Administración o sus entidades realicen funciones mercantiles (es decir, todas aquellas que no son de satisfacción de interés general o por supuesto estrictamente públicas) entonces será válida la aplicación del Derecho privado tanto en lo material como en lo procesal. Esta alusión no significa en realidad una llamada a la jurisdicción civil. Su interés está más bien en que en estos casos el propio control de legalidad (tema que preocupa al Derecho público) será conseguido fundamentalmente por la aplicación del Derecho de la competencia y, en particular, por la sujeción a ciertos principios de igualdad, proporcionalidad, transparencia que conlleva la técnica del abuso de posición dominante. Este control desde las organizaciones del Derecho de la competencia, se ha revelado asimismo más efectivo que aquel otro, propuesto por algún sector doctrinal (en especial en Alemania) de la aplicación de los derechos fundamentales en este tipo de situaciones, que no se ha impuesto en la práctica de modo alguno.

Pero al margen de esta reducida parcela de la CNC es claro que el sistema de control sobre las adjudicaciones contractuales está protagonizado por la nueva presencia del Tribunal Administrativo Central de Recursos contractuales (art. 311 de la Ley 34/2010, de 5 de agosto) y tribunales similares a nivel regional y por supuesto por la jurisdicción contencioso-administrativa.

\section{NUEVA REFERENCIA A LA JURISDICCIÓN CIVIL}

La jurisdicción civil, sin embargo, tras la LCSP 30/2007 y el actual TRLCSP 3/2011 ha irrumplido también de alguna forma en el sistema de control de las adjudicaciones contractuales en este ámbito público, considerando que dicha normativa ha tenido la ocurrencia de atribuir a dicha jurisdicción el control de las adjudicaciones de las entidades dependientes de la Administración u organismos públicos cuando éstos desarrollen función de satisfacción de interés general, en caso de que dichas adjudicaciones no superen los umbrales comunitarios, es decir, cuando no sean regulación armonizada, sino adjudicación en clave de puro Derecho interno. En cambio, cuando la adjudicación adquiera relevancia especial, es decir, aquélla esté afectada por los umbrales de la regulación armonizada será obligado el conocimiento de la jurisdicción contencioso-administrativa. Desde el punto de vista del Derecho europeo es claro que éste no se entromete en este tipo de cuestiones, si bien es cierto que ha provocado el debido rigor en el control de las adjudicaciones de estas entidades obligando a sujetarse a las regulaciones generales de adjudicación en tanto en cuanto realicen este tipo de funciones públicas. La forma jurídica es irrelevante, lo que importa es el tipo de función, previa adscripción de la entidad a una Administración territorial.

Si esta solución se compara con la laguna existente tradicionalmente en este ámbito en el Derecho español -sin duda éste era uno de los puntos débiles de nuestro sistema jurídico- es claro que se ha producido un gran avance. Las directivas han obligado a desarrollar un control sobre tales adjudicaciones y el legislador español ha realizado este posible modelo que, más concretamente, se reitera con los matices 
debidos en las famosas instrucciones de contratación pública que durante los últimos años han venido dictándose para regir la contratación de estas entidades.

En la práctica, sin embargo, incluso en estos casos en que en principio ha de conocer la jurisdicción civil puede ocurrir que termine conociendo la jurisdicción contencioso-administrativa al poder intervenir junto a la sociedad mercantil el Ayuntamiento en cuestión (siendo el Presidente de la sociedad pública el propio Alcalde del Ayuntamiento, o porque se otorgue en la resolución del adjudicador un derecho a la interposición de un recurso administrativo).

Y por supuesto la jurisdicción civil podrá concoer de los efectos y extinción y fase de ejecución de los contratos civiles de la Administración y con mayor motivos de sus entidades dependientes. Pero esto, evidentemente, no afecta al sistema en cuanto tal de control que estamos comentando.

\section{DE CÓMO LA JURISDICCIÓN CONTENCIOSO-ADMINISTRATIVA RESUELVE EN ESPAÑA PERFECTAMENTE ASUNTOS QUE PODRÍAN INCARDINARSE, INCLUSO PROCESALMENTE, BAJO LA ÓRBITA ORGANIZATIVA DEL DERECHO DE LA COMPETENCIA}

En consecuencia, la concurrencia efectiva, que es la idea de sistema de las directivas europeas y, más allá de un Derecho europeo basado en el quid de la competencia, se realiza en el Derecho español, fundamentalmente, por el Derecho administrativo $y$, en lo procesal, por la jurisdicción contencioso-administrativa o los nuevos tribunales igualmente administrativos de control de adjudicaciones contractuales.

Son muy numerosos los posibles ejemplos de cómo la jurisdicción contenciosoadministrativa resuelve asuntos con marcado carácter concurrencial. En el fondo es muy común que en este tipo de asuntos de adjudicaciones contractuales estén presentes de manera más o menos intensa aspectos de este tipo concurrencial o de Derecho de la competencia. Esto ocurre por ejemplo en los casos de posibles exclusiones indebidas a licitadores en los procedimientos de licitación, tema en el que vienen insistiendo tanto las últimas reformas de las directivas europeas de contratación pública ${ }^{8}$ como la Ley española 30/2010. La concurrencia efectiva obliga a la tutela de quienes han sido licitadores pero también de los llamados "licitadores potenciales" que, si no lo han sido, es porque se les ha impedido indebidamente participar en la licitación. Suelen ser casos en que se obvia el procedimiento debido, privando a un

8 Véase asismismo en este sentido la COMUNICACIÓN INTERPRETATIVA DE LA COMISIÓN sobre el Derecho comunitario aplicable en la adjudicación de contratos no cubiertos o sólo parcialmente cubiertos por las Directivas sobre contratación pública (2006/C 179/02).

9 “Podrá interponer el correspondiente recurso especial en materia de contratación toda perso60 na física o jurídica cuyos derechos o intereses legítimos se hayan visto pe 
potencial licitador de un derecho a recurrir la adjudicación. Casos de ausencia de competencia de base.

Como decimos, este tema en el Derecho español se soluciona a través del Derecho administrativo, pese a su posible relación incluso esencial con el Derecho de la competencia alentado por la Unión Europea. Para la Sala tercera del TS estos derechos son tutelables. Es lo que denomina "licitador potencial" a quien se reconoce legitimación mediante una interpretación flexible del interés legítimo (SSTS de 23 de noviembre de 2000, RJ 2000|9622; y de 21 de diciembre de 2001 RJ 2002(10527).

En la primera de las citadas dice el Supremo que "sí parece concurrir en éste un cierto grado de interés legítimo cuando pretende una declaración de nulidad de las enajenaciones con base en los fundamentos que esgrime y con la consiguiente posibilidad de que, en su beneficio, pudiera convocarse el concurso que postula y en el que, en su caso, él pudiera intervenir, de modo que, prescindiendo ahora de cualquier aspecto que con el fondo se relacione, existe legitimación en el demandante al ponderar que en lo que se refiere al interés legítimo".

Y para ello se basa el Alto Tribunal en que este interés legítimo es "más amplio que el de directo al que expresamente se refería en su anterior redacción el art. 28, 1, a) de la Ley Reguladora de esta Jurisdicción en su versión aplicable, ha de tomarse en consideración que aquél equivale a la titularidad potencial de una posición de ventaja o de una utilidad jurídica por parte de quien ejercita la pretensión y que se materializaría, en su caso, al prosperar ésta (sentencias del Tribunal Constitucional 143/1987 [RTC 1987, 143], 60/1982 [RTC 1982, 60], 62/1983 [RTC 1983, 62], 257/1988 [RTC 1988, 257] y 97/1991 [RTC 1991, 97], y de esta Sala de 22 de diciembre de 1997 [RJ 1998, 688], entre otras), debiendo entenderse que tienen tal interés legítimo aquellas personas que son o pueden ser titulares de un interés propio distinto del de cualquier ciudadano, porque tal concepto abarca cualquier situación jurídica individualizada que se caracterice, por un lado, por singularizar la esfera jurídica de una persona respecto de las de la generalidad de los ciudadanos o administrados en sus relaciones con la Administración Pública, y dotada, por otra parte, de consistencia y lógica jurídico-administrativa propias, independientes de su conexión o derivación con verdaderos derechos subjetivos -que se reconocerán o no, pero por razones de fondo-, aunque no baste el deseo de que prevalezca la legalidad, pues ello sólo es suficiente en supuestos de acción popular o en los más limitados y específicamente previstos de acción pública, lo que obliga a que la respuesta al problema de la legitimación deba ser casuística, aunque, en todo caso, no pueda negarse cuando exige cualquier examen del fondo de la cuestión, porque entonces se halla en íntima relación con ésta, que debe resolverse en el cauce del examen que corresponde, lo que ha de determinar el rechazo de la causa de inadmisibilidad que se invocó” ${ }^{10}$.

10 Véase también la ilustrativa STSJ de Canarias (sede de Santa Cruz) de 20 de junio de 2005 (RJ 746). Otras citas en Escrihuela Morales, La contratación del sector público, Madrid 2007, p.184. 
Todo se mueve, por el momento, en una lógica pura de Derecho administrativo, no sólo en lo material y en lo procesal sino también en lo consultivo (Informe de la Junta Consultiva de Contratación administrativa 33/09, sobre "participación en un procedimiento negociado sin publicidad").

En la jurisprudencia constitucional puede citarse la STC de 10 de noviembre de 2008: "en el supuesto ahora examinado, si bien la sociedad demandante no impugnó las bases de la convocatoria del concurso ni participó en el mismo, lo cierto es que, precisamente, lo que se alegó en el recurso contencioso-administrativo es que la convocatoria se había hecho en unos términos deliberadamente imprecisos con el fin de ocultar la verdadera intención de la Administración, que no era otra que la de evitar la participación de empresas distintas de la que, a la postre, resultó adjudicataria. En consecuencia, debemos considerar que no es compatible con el derecho a la tutela judicial efectiva el rechazo ad limine del recurso contencioso-administrativo sin ponderar si la falta de impugnación y de participación de la demandante en el concurso público tiene su origen en la propia actuación administrativa".

Lo significativo es que este mismo control se desarrolla en Europa por un Tribunal (el de la Unión Europea) que viene a tener una mayor similitud con nuestra CNC (en cuanto al tipo de control y modos en que se desarrolla) que con la jurisdicción contencioso-administrativa, partiendo de que dicho tribunal ha de enjuiciar materialmente un Derecho como el de la competencia basado en una pura lógica de regulación pública de mercado.

Sobre la materia que estamos comentando puede citarse la sentencia de 11 de octubre de 2007 (Asunto C-241/06 ${ }^{11}$ ) o la sentencia de 7 de diciembre de 2000 (asuntos C-324/98 Telaustria 2000, Rec. I-10745 ${ }^{12}$ ) o la sentencia de 13 de septiembre de

11 "Ha de considerarse, habida cuenta de la existencia de un plazo de caducidad para interponer recurso, que un anuncio de contrato falto de toda información sobre el valor estimado del contrato, seguido de un comportamiento evasivo de la entidad adjudicadora frente a las cuestiones de un licitador potencial, como el que se da en el litigio principal, dificultó excesivamente que el licitador perjudicado ejercitase los derechos que el ordenamiento jurídico comunitario le confiere (en este sentido, véase la sentencia Santex, antes citada, apartado 61)".

12 Teleaustria. C-324/98. 7-12-2000. "La Directiva 93/38, adoptada el mismo día que la Directiva 93/37, no contiene disposición alguna sobre las concesiones de servicios públicos. De ello se deduce que el legislador comunitario decidió no incluirlas en el ámbito de aplicación de la Directiva 93/38. Si su intención hubiera sido otra, lo habría indicado expresamente, tal como hizo al adoptar la Directiva 93/37. A este respecto procede señalar que, pese a que, en el estado actual del Derecho comunitario, tales contratos se encuentran excluidos del ámbito de aplicación de la Directiva 93/38, las entidades contratantes que los celebren están obligadas no obstante a respetar, en general, las normas fundamentales del Tratado y, en especial, el principio de no discriminación por razón de la nacionalidad. En efecto, tal como declaró el Tribunal de Justicia en la sentencia de 18 de noviembre de 1999, Unitron Scandinavia y 3-S (C-275/98, Rec. p. I-8291), apartado 31, dicho principio implica, en particular, una obligación de transparencia que permite que la entidad adjudicadora se asegure de que el mencionado principio es respetado. La obligación de transparencia que recae sobre la entidad adjudicadora consiste en garantizar, en beneficio de todo licitador 62 imparcialidad de los procedimientos de adjudicación". 
2007 C-260/04 (Comisión contra Italia) ${ }^{13}$ o la sentencia de 18 de enero de 2007 (asunto Auroux. C-220/05), etc. La jurisprudencia del TJCE insiste en la necesidad de "garantizar, en beneficio de todo licitador potencial, una publicidad adecuada que permita abrir a la competencia el mercado de servicios y controlar la imparcialidad de los procedimientos de adjudicación".

En suma, los principios de publicidad, concurrencia y vinculación a la mejor oferta se desarrollan sobre esta base, así como los de igualdad de trato y no discriminación, además de los de transparencia o racionalidad, donde la cuestión se aprecia más claramente aún.

\section{IDEA FINAL}

La jurisdicción contencioso-administrativa y el Derecho administrativo vienen configurando el sistema de control de las adjudicaciones contractuales. El nuevo Tribunal Administrativo Central de Recursos administrativos y órganos similares territoriales arraigan el Derecho administrativo en el ámbito contractual, pero pueden llegar a afectar el significado de la jurisdicción contencioso-administrativa. En todo caso, aumentan las exigencias y, en el Derecho español, esto significa que aumenta el rigor del Derecho administrativo, mientras que en otros países se oculta esta realidad en la medida de lo posible prefiriéndose enfocar la materia jurídica desde el punto de vista del Derecho de la competencia. Pese a posibles referencias en el Derecho comparado, las organizaciones del Derecho de la competencia no suponen actualmente en España crisis alguna del modelo tradicional, habiéndose llegado a la asunción de distintas parcelas o ámbitos de control. El reto en realidad es que las resoluciones que se adopten se adecuen, mejor que en el pasado, a los intereses públicos y a los de justicia de los licitadores.

13 "Las autoridades públicas que celebren contratos de concesión de servicios públicos están obligadas a respetar, en general, las normas fundamentales del Tratado CE, entre ellas los artículos 43 CE y $49 \mathrm{CE}, \mathrm{y}$, en especial, el principio de no discriminación por razón de la nacionalidad, que constituyen una expresión particular del principio de igualdad de trato. Los principios de igualdad de trato y de no discriminación por razón de nacionalidad implican, en particular, una obligación de transparencia que consiste en garantizar, en beneficio de todo licitador potencial, una publicidad adecuada que permita abrir a la competencia la concesión de servicios y controlar la imparcialidad de los procedimientos de adjudicación”. 
